\title{
Alveolar bone pathology associated with delayed permanent tooth eruption in a cat - a case study
}

\author{
Anna S. Spirina, David A. Crossley \\ Veterinary Clinic “Dentalvet”, Moscow, Russia \\ Received May 18, 2020 \\ Accepted November 9, 2021
}

\begin{abstract}
A young cat was presented with oral discomfort, gingival swelling and delayed eruption of the permanent dentition. Radiography confirmed the presence of unerupted teeth and identified alveolar bone pathology. Operculotomy was performed to expose the embedded teeth. Eruption and the potential etiology of disturbances to normal dental eruption are discussed.
\end{abstract}

Feline gingival overgrowth, alveolar exostosis, teething cyst

Many mammals possess two successive sets of teeth (the diphyodont condition). The initially formed "deciduous" dentition being followed by eruption of a "permanent" one (Hillson 2005; Ungar 2010). Dental eruption is a unique physiological event and the permanent tooth is the only organ that may develop after birth. A common feature of mammalian dentition is the functional, and related morphological, specialization of the teeth, a condition referred to as heterodonty (Ungar 2010). Of the four different tooth types of mammals (Plate VIII, Fig. 1), the incisors, canines, and premolars undergo replacement, while there is only a single generation of permanent molars (Hills on 2005; Ungar 2010). The main functions of dentition are food acquisition and processing, but they also play a role in grooming and the social life of various mammal species (Ungar 2010). Deviations from the normal physiology, development, number, position, morphology and/or structure of teeth can negatively affect body condition, health, survival, and lifetime reproductive success (Verstraete et al. 1996a,b).

\section{Case description}

A 1-year-old intact male British Shorthair cat was presented for oral examination as the owners had noticed increasing oral discomfort and gingival swelling. The cat was small with short legs, being very much behind the growth and development of his litter mates.

On oral examination, the cat's jaw length was normal, however, the right mandibular canine tooth was abnormally positioned (type 1 malocclusion) with apparent absence or incomplete eruption of most of the other permanent teeth. The gingiva was swollen over much of the dental arcades, but, apart from an irregular surface (and very mild marginal gingivitis around the maxillary canine teeth), otherwise visually appeared clinically healthy (Plate VIII, Fig. 2). The swollen gingiva was firm on palpation and well vascularized. Teething cysts with fluid content were found in the region of the missing maxillary first molar teeth. It was suspected that the swollen gingiva was hiding those permanent teeth that were not visible (i.e. all incisors, the third and fourth maxillary premolars), as other teeth (the mandibular molars and premolars) were partially covered by the swollen gingiva.

The rest of the physical examination and pre-operative workup were unremarkable, so the cat was anaesthetised to permit a more thorough examination, including probing, charting

Address for correspondence:

Anna S. Spirina

Veterinary Clinic "Dentalvet"

Street Aviakonstruktora Mile 2/1

109431 Russia, Moscow 
and intraoral radiography, prior to the required oral hygiene procedure (dental scaling and polishing) and any other necessary treatment. Limb radiography was also recommended, however, this was declined as the owner was primarily concerned with the oral pain.

Treatment outline

Anaesthesia

Cat was premedicated with promethazine (Pipolphen, EGIS, Hungary) (1 mg/kg i.m.), atropine sulphate (Atropine, Belmedpreparaty, Republic of Belarus) (20 mg/kg s.c.), plus diazepam (Diazepam Relanium, POLFA, Warsaw Poland) (2 mg/kg i.m.). Once this had taken effect, general anaesthesia was induced using ketamine hydrochloride (Ketamin, Moscow Endocrine Plant, Moscow) (3 mg/kg i.m.) and medetomidine (Meditin, Api-san, Russia) (0.04 mg/kg i.m.). This was followed by endotracheal intubation to permit anaesthetic maintenance by inhalation using $0.5-1 \%$ isoflurane (Foran, Abbott Laboratories, United Kingdom) in oxygen ( $1 \mathrm{l} / \mathrm{min})$. Ringer's solution was infused at a flow rate of $20 \mathrm{ml} / \mathrm{h}$ through a 22 -gauge intravenous catheter from induction to recovery. Patient indicators were monitored using reflex assessment, auscultation and electrocardiography and body temperature was maintained using heating pads and blankets. Additional pain control was achieved by performing maxillary and mandibular nerve blocks using articaine (Ultracaine, Sanofi-Aventis, France) $(2.0 \mathrm{mg} / \mathrm{kg})$.

\section{Dental radiography}

Following dental charting, scaling and polishing of the visible teeth and disinfection of the oral cavity with a $0.05 \%$ solution of chlorhexidine bigluconate (Chlorhexidine $0.05 \%$, Rosbio, Russia), the presence of unerupted teeth beneath the swollen gingiva was confirmed by intraoral dental radiography (Plate IX, Fig. 3). This also revealed the presence of abnormal bone within some of the areas of gingival swelling, areas having a nodular appearance superficially resembling complex odontoma. In places excessive bone extended over the crowns of the unerupted teeth.

\section{Treatment plan}

It was decided to perform gingivoplasty where there was excessive gingival soft tissue abutting erupted teeth, aiming to try to establish a near normal gingival contour as this would enhance natural tooth cleaning and reduce the risk of secondary periodontal disease (Lewis and Reiter 2005).

Immature unerupted/impacted permanent teeth often retain the ability to resume eruption (Bassigny 1990), so it was decided to perform operculotomy on these teeth if practical, exposing the crown and creating an unobstructed eruption path. This also prevents eruption cyst enlargement. Due to the extensive areas involved and the need to remove bone as well as soft tissues, it was decided to stage the treatment, initially operating on the right side of the mouth and, if the treatment was successful on this side, completing treatment on the other side a month later, once healing was complete on the first side.

\section{Procedures}

Following radiographic identification of the areas with bone pathology and site disinfection, the maxillary gingiva was incised with a No.15 scalpel and the tissue reflected using a periosteal elevator to create envelope flaps palatally and buccally, deep enough to expose the affected areas. Excess soft tissue was removed to aid visibility, being careful to retain plenty of tissue for flap closure where needed. Where there was bone covering the teeth, it was cut away using a $1 \mathrm{~mm}$ round bur in a low speed handpiece whilst irrigating the area with Ringer's solution for cooling. The crown of the maxillary third premolar appeared normal once the covering bone was removed. The fourth maxillary premolar had an irregularly 
shaped crown and evidence of resorption at the cementoenamel junction, so the tooth was sectioned and extracted along with the adjacent vestigial molar tooth. A similar approach was used to permit osteoplasty, recontouring the thickened bone, around the mandibular canine tooth. The extraction sites were sutured closed with 5-0 PGA (PGA, Volot, Russia) (Plate X, Fig. 4).

Gingivoplasty was performed around the right mandibular molar and premolar teeth, the right maxillary canine tooth and all the maxillary incisor teeth using a safe ended bur in a high-speed handpiece with water cooling. These areas were then treated with policresulen $36 \%$ (Polfa, Poland) for its haemostatic and antiseptic effects (Plate XI, Fig. 5).

A fragment (approximately $10 \times 8 \times 2 \mathrm{~mm}$ ) of the abnormal bone removed from the $\mathrm{R}$ maxilla was submitted for histopathology, the results reporting benign new bone growth with exostosis. Unfortunately the excised gingival soft tissues were mislaid and so could not be submitted to the lab.

\section{Postoperative care}

The cat's recovery from anaesthesia was uneventful and the cat was discharged the same day with tramadol (Tramal, Polfarma, Russia) $(2 \mathrm{mg} / \mathrm{kg}$ i.m., 3 day) and meloxicam (Meloxidil, Ceva Sante Animale, France) $(0.1 \mathrm{mg} / \mathrm{kg}$ p.o., 5 days) for post-operative analgesia. The owner was supplied with a dental adhesive paste containing benzyldimethyl and solcoseryl (Solcoseryl adhesive dental paste, Legacy, Switzerland) to be applied locally daily for 7 days, if possible, to provide ongoing physical protection of the extraction site. Soft food was advised for the first 3 days.

\section{Second procedure}

At the follow-up examination the following month, healing was reported to have progressed rapidly and the cat was eating better, appearing more comfortable though occasionally still showing signs of pain. Overall the treated areas appeared much more normal with no recurrence of gingival overgrowth but there was a minor degree of marginal gingivitis (Plate XI, Fig. 6). There was only slight progression of the gingival swelling in the untreated areas. As the first stage treatment appeared successful, the cat was admitted for treatment of the left side of his mouth.

The anaesthesia was performed using the same protocol as previously. The teeth were scaled, the oral cavity disinfected and further dental radiographs obtained. These showed no evidence of further exostosis on the previously treated side and slight progression on untreated areas.

Surgical intervention closely matched that performed previously with osteoplasty and extraction of the maxillary fourth premolar (root deformities were present) and molar, plus gingivoplasty around the mandibular incisors, canine, premolars and molar (Plate XII, Fig. 7).

\section{Follow-up}

The gingiva again healed rapidly and appeared clinically normal 5 weeks after the second procedure. At this stage the cat was reported to have no signs of oral discomfort and was eating without any difficulties. So far there was no sign of further eruption of the previously embedded teeth. As all appeared well it was not considered necessary to anaesthetise the cat for control radiographs, however, this will be advised should it require anaesthesia in the future. The owner reported that the cat was fit and well, though still smaller than his litter mates, with no recurrence of gingival swelling 6 months after the second procedure.

\section{Discussion}

Developmental deviations from the normal number, size, shape, and position of teeth mostly have genetic causes, but can also originate from disturbance by other factors, such as 
physical injury, disease processes, nutritional deficiencies or the impact of toxic substances (Miles and Grigson 1990; Slootweg 2013). Genetic and non-genetic developmental alterations must be distinguished from pathological (or surgical) changes occurring during or after tooth eruption.

Tooth eruption is defined as the movement of the tooth from its original site of development within the alveolar process to its functional position in the oral cavity (Marks and Schroeder 1996). In the 1980s, many teams looked at the mechanisms behind dental eruption; their work has highlighted complex interactions between osteoblasts, osteoclasts, and the dental follicle, however, despite vast amounts of research, the exact mechanism of tooth eruption remains unknown. Theories regarding the mechanism of eruption have involved changes in interstitial fluid pressure (Aladdin and Burn-Murdoch 1985), contraction of collagen fibres and the properties of the dental follicle (Marks et al. 1983), all now largely discounted as being major factors. These studies have opened the way for the discovery of multiple genetic, molecular, and tissue interactions that occur during dental eruption resulting in differential growth between the developing tooth and surrounding tissues. Not only are these interactions essential for the smooth running of the process of eruption, their timing and coordination are precisely regulated. A disruption of the eruption process can occur in the context of systemic or genetic disorders resulting in a clinical picture that can range from a simple delay to a complete failure of eruption or even tooth agenesis. For example, in osteopetrosis, teeth form but are unable to erupt as the overlying bone is not resorbed to form an eruption pathway (Marks 1989). Sometimes it has been study of such pathological conditions that has revealed some of the essential interactions that occur during tooth eruption.

A delay or failure of tooth eruption may be the first, if not the only, expression of a local or general pathology (Choukroune 2017). In a clinical setting, precise assessment of the pattern of disruption of eruption helps suggest possible aetiologies and provides a working diagnosis, allowing an appropriate treatment plan to be devised (Choukroune 2017).

\section{Pathologies associated with eruption disorders}

Vitamin A and vitamin D deficiencies during periods of growth are associated with tooth development and eruption abnormalities. In the absence of limb radiographs it is uncertain, but the lack of limb bowing and the normal appearance of the tooth enamel suggest that vitamin D deficiency can be ruled out in the described case. Altered alveolar bone formation, delayed eruption and hyperplastic gingival tissues have been described in experimental rats deprived of vitamin A (Shafer 1983), however, the cat and its littermates were fed the same diet and only the one developed a problem so both vitamin A and D deficiencies can be ruled out.

When endocrine diseases such as hypothyroidism and hypoparathyroidism occur during development they have a range of systemic and local effects, including eruption delays (Suri at al. 2004). In the latter case, the teeth typically show abnormalities of mineralisation resulting in enamel hypoplasia. The tendency for hypocalcaemia generally results in stunted growth, poor bone quality and, if hypocalcaemia is severe, muscular tremors and even seizures (Peters on 2013; Koenig 2013; Kamarthi et al. 2013). Whilst the cat described in this case report was stunted and had disturbed eruption, tooth and jaw bone quality appeared normal, there were no reports of seizures of muscle tremors so this is unlikely to be the aetiology of its problems. In congenital hypothyroidism, growth, including that of the face and jaw, is stunted resulting in short legs and jaw, with delayed eruption and dental overcrowding (Dudhia and Dudhia 2014). Skin condition is usually affected with poor hair growth and quality (Gross at al. 2005). The cat had a good coat and only the incisors were overcrowded, so hypothyroidism is also unlikely to have been involved. 
Many medications, including those that inhibit the prostaglandin pathways, can affect bone metabolism. For this reason Meloxicam is not recommended for use in immature animals (https://www.drugs.com/vet/metacam-oral-suspension.html; Lehr et al. 2010). Meloxicam reduces osteoclastic and odontoclastic activity in periodontal tissues resulting in slower tooth movement and less root resorption being seen during orthodontic treatments (Kirschneck at al. 2017). This effect is likely to also affect tooth eruption. As there was no history of drug use in the described case prior to onset of clinical signs, this was not the cause of the cat's problems. As the cat was already one year old when seen, use of meloxicam for postoperative analgesia was not contraindicated.

There are many patterns of delayed eruption of the permanent dentition, both syndromic and non-syndromic (Choukroune 2017). Primary failure of eruption (Proffit and Vig 1981) describes a situation in which the tooth fails to erupt due to a malfunction of the eruption mechanism. The eruption path of affected teeth forms well with no other bone changes but the tooth does not erupt, or only partially with no evidence of ankylosis preventing tooth movement. This does not match the pattern seen in the described cat where there was new bone formation and exostosis. The exostosis seen in the cat does not resemble human "jaw exostosis" which is a rare human condition usually occurring caudal to the wisdom teeth. These exostoses may be the result of chronic local trauma. The pattern of changes in the cat does not match this human condition and it seems unlikely that chronic trauma was the aetiology of the cat's eruption problem and new bone formation.

\section{Conclusion}

Dental eruption is a very finely regulated process with many genes being active in cells of the dental follicle, releasing regulatory molecules to control both tooth development, formation of the eruption pathway and eruption itself. Many things can affect these processes resulting in various patterns of disruption of eruption. So far, it has not been possible to determine a cause of this cat's problems so they remain idiopathic.

\section{References}

Aladdin QI, Burn-Murdoch RA 1985: The effect of procedures intended to alter the interstitial fluid pressure in the sockets of resected rat incisors we their eruption rate. Arch Oral Biol 30: 525-530

Bassigny F 1990: Orthodontic effects of tooth injury to the permanent and temporary incisors of children and the adolescent [corrected, in French]. Rev Odontostomatol (Paris) 19: 511-538, Erratum in: Rev Odontostomatol (Paris) 20: 147

Choukroune C 2017: Tooth eruption disorders associated with systemic and genetic diseases: clinical guide. J Dentofacial Anom Orthod 20: 402

Dudhia SB, Dudhia BB 2014: Undetected hypothyroidism: A rare dental diagnosis. J Oral Maxillofac Pathol 18: $315-319$

Gross TL, Ihrke PJ, Walder EJ, Affolter VK 2005: Skin Diseases of the Dog and Cat: Clinical and Histopathologic Diagnosis. Second edn. Blackwell Science Ltd., Oxford, 932 p.

Hillson S 2005: Teeth. Second edn. Cambridge University Press, Cambridge, 373 p.

Drugs.com Web site. Available at: www.drugs.com/vet/metacam-oral-suspension.html. Updated: 2020-05-01

Kamarthi N, Venkatraman, S, Patil PB 2013: Dental findings in the diagnosis of idiopathic hypoparathyroidism. Ann Saudi Med 33: 411-413

Kirschneck C, Meier M, Bauer K, Proff P, Fanghänel J 2017: Meloxicam medication reduces orthodontically induced dental root resorption and tooth movement velocity: a combined in vivo and in vitro study of dentalperiodontal cells and tissue. Cell Tissue Res 368: 61-78

Koenig A 2013: Endocrine emergencies in dogs and cats. Vet Clin North Am Small Anim 43: 869-897

Lehr T, Narbe R, Jöns O, Kloft C, Staab A 2010: Population pharmacokinetic modelling and simulation of single and multiple dose administration of meloxicam in cats. J Vet Pharmacol Ther 33: 277-286

Lewis JR, Reiter AM 2005: Management of generalized gingival enlargement in a dog - case report and literature review. J Vet Dent 22: 160-169

Marks SC 1989: Osteoclast biology: lessons from mammalian mutations. Am J Med Genet 34: 43-54

Marks SC, Schroeder HE 1996: Tooth eruption: theories and facts. Anat Rec 245: 374-393

Marks SC, Cahill DR, Wise GE 1983: The cytology of the dental follicle and adjacent alveolar bone during tooth eruption in the dog. Am J Anat 168: 277-289 
Miles AEW, Grigson C 1990: Colyer's Variations and Diseases of the Teeth of Animals. Second edn. Cambridge University Press, Cambridge, $672 \mathrm{p}$.

Peterson ME 2013: Hypocalcemia in Dogs and Cats. MSD Veterinary Manual. https://www.msdvetmanual.com Proffit WR, Vig KW 1981: Primary failure of eruption: a possible cause of posterior open-bite. Am J Orthod 80: 173-190

Shafer WG 1983: Textbook of Oral Pathology. Fourth edn. WB Saunders Co, Philadelphia, 917 p.

Slootweg PJ 2013: Dental Pathology: A Practical Introduction. Second edn. Springer-Verlag, Berlin-Heidelberg, $170 \mathrm{p}$.

Suri L, Gagari E, Vastardis H 2004: Delayed tooth eruption: pathogenesis, diagnosis, and treatment. A literature review. Am J Orthod Dentofacial Orthop 126: 432-445

Ungar PS 2010: Mammal Teeth. Origin, Evolution, and Diversity. Johns Hopkins University Press, Baltimore, $320 \mathrm{p}$.

Verstraete FJ, van Aarde RJ, Nieuwoudt BA, Mauer E, Kass PH 1996a: The dental pathology of feral cats on Marion Island, part I. Congenital, developmental and traumatic abnormalities. J Comp Pathol 115: 265-282

Verstraete FJ, van Aarde RJ, Nieuwoudt BA, Mauer E, Kass PH. 1996b: The dental pathology of feral cats on Marion Island, part II: periodontitis, external odontoclastic resorption lesions and mandibular thickening. J Comp Pathol 115: 283-297 
Plate VIII

Spirina A. S. et al.: Alveolar ... pp. 415-420

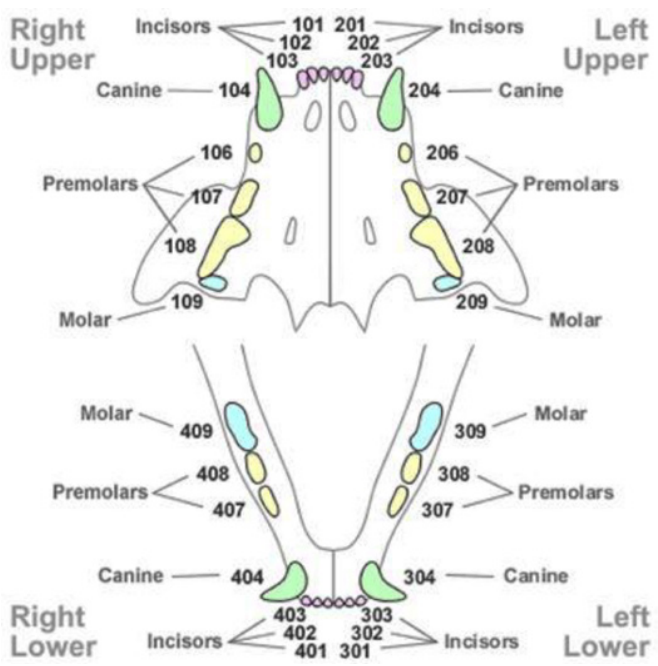

Fig. 1. Adult feline dentition and modified Triadan tooth notation system as applied to the cat.
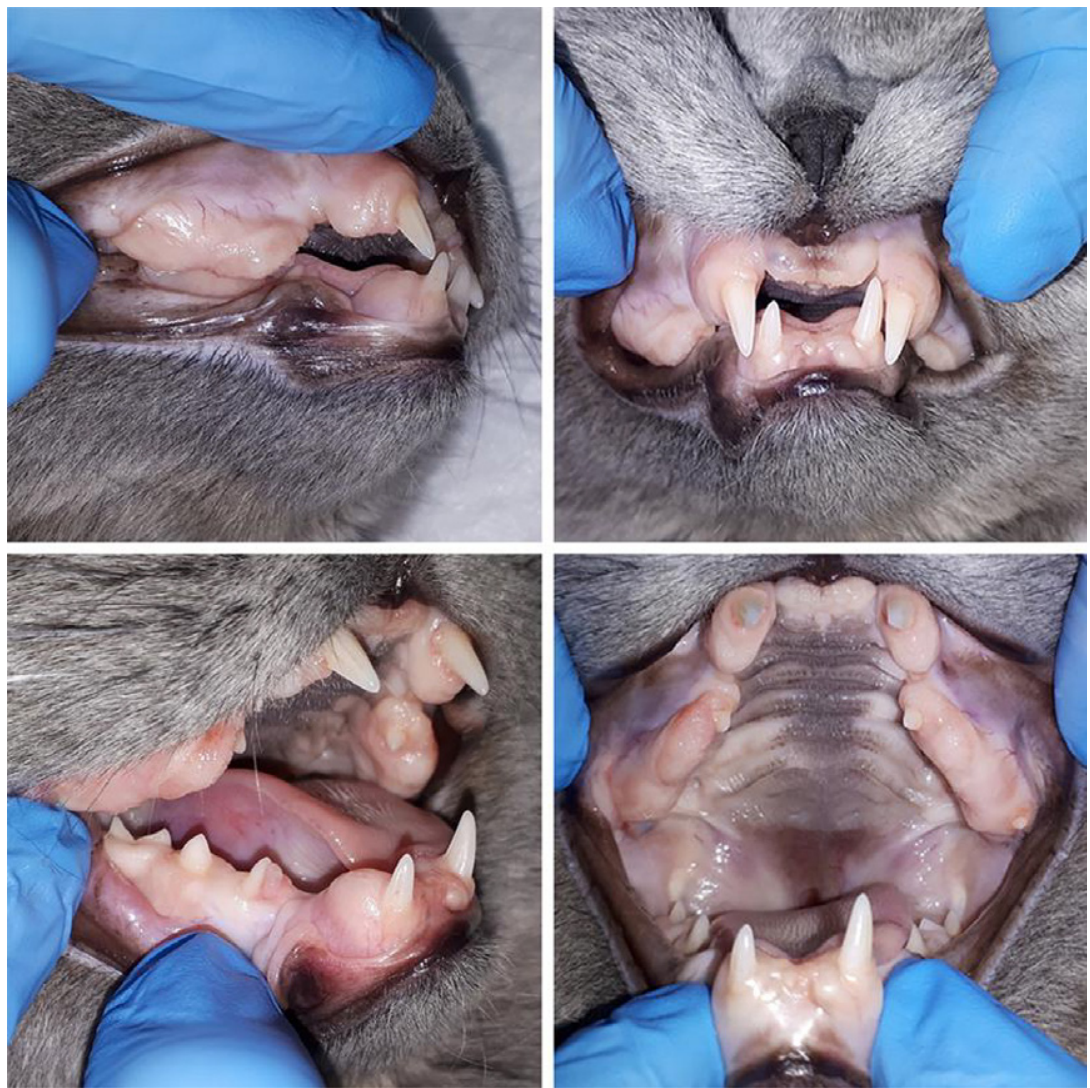

Fig. 2. Oral photographs illustrating the clinical appearance prior to treatment (November 25, 2018) 


\section{Plate IX}

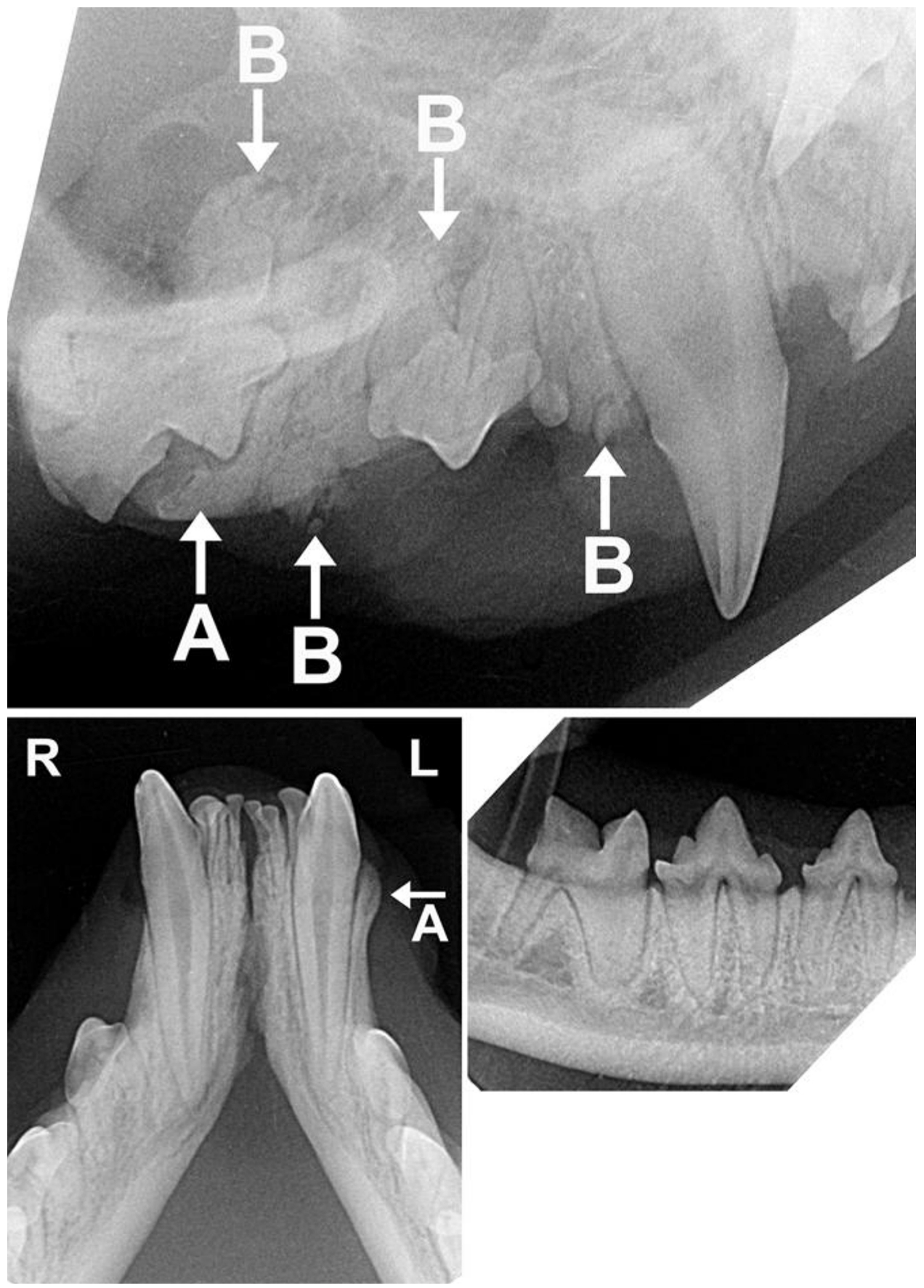

Fig. 3. Dental radiograph, right maxilla and mandibles illustrating the bone abnormalities (November 25, 2018) A - uniformly thickened bone; B - nodular bone. Note the normal bone contours around the mandibular premolars and molar tooth. 

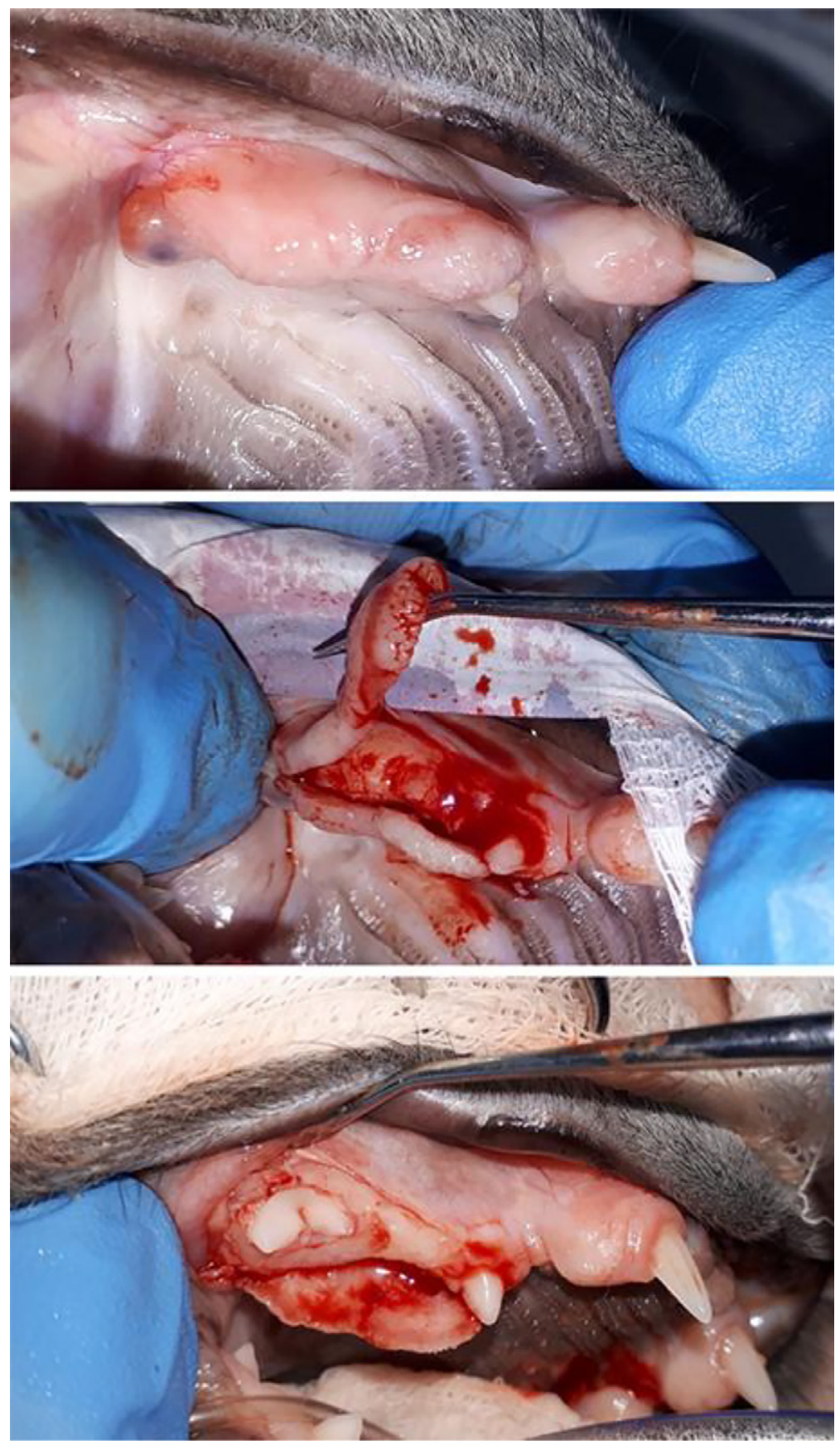

Fig. 4. Surgical access for bone removal (November 25, 2018)

Top: Swollen gingiva overlying the R maxillary premolars; Middle: Gingival flap raised exposing bone covering the $4^{\text {th }}$ premolar tooth and excess gingival tissue being excised; Bottom: Following osteoplasty to expose the $4^{\text {th }}$ premolar tooth 

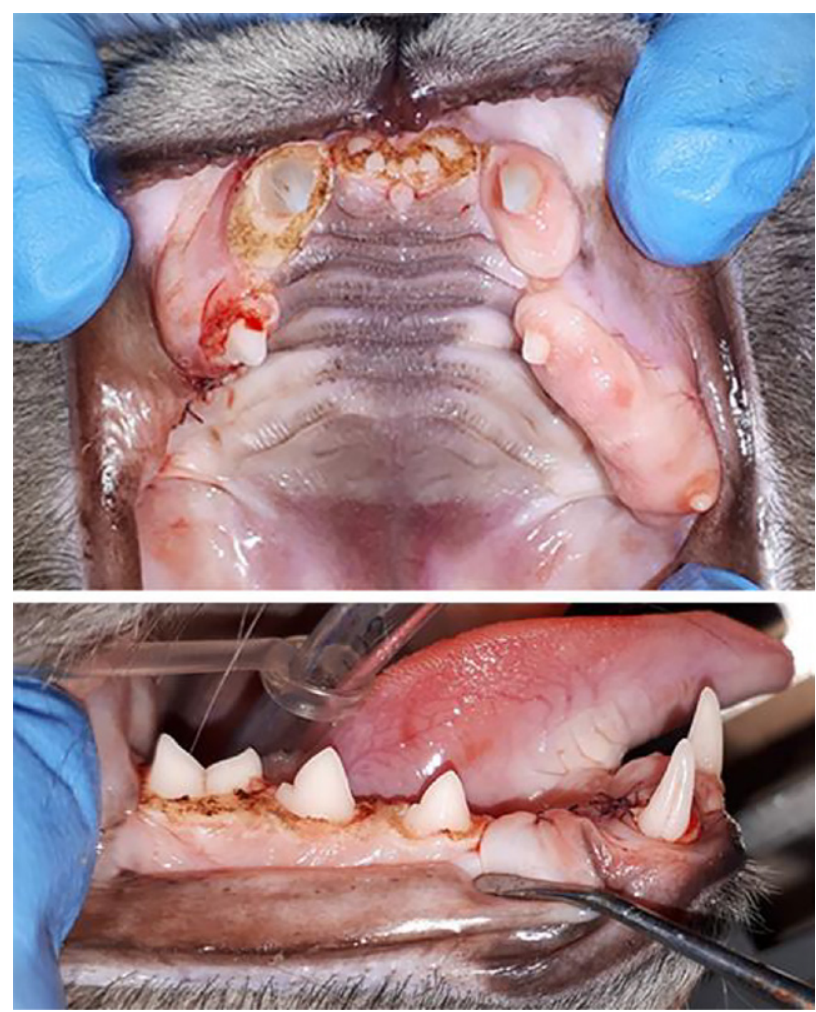

Fig. 5. Gingivoplasty performed using diathermy (November 25, 2018)

The gingiva was recontoured around the maxillary incisors, the right maxillary canine, mandibular premolars and molar tooth.

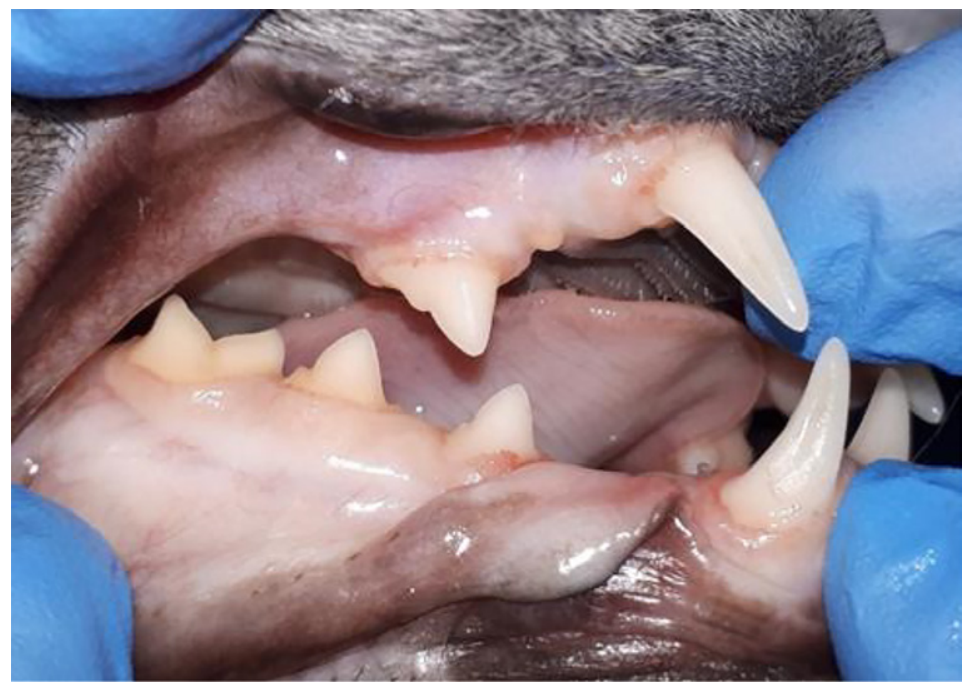

Fig. 6. Photograph showing healing of the right side of the mouth (December 23, 2018) 
Plate XII
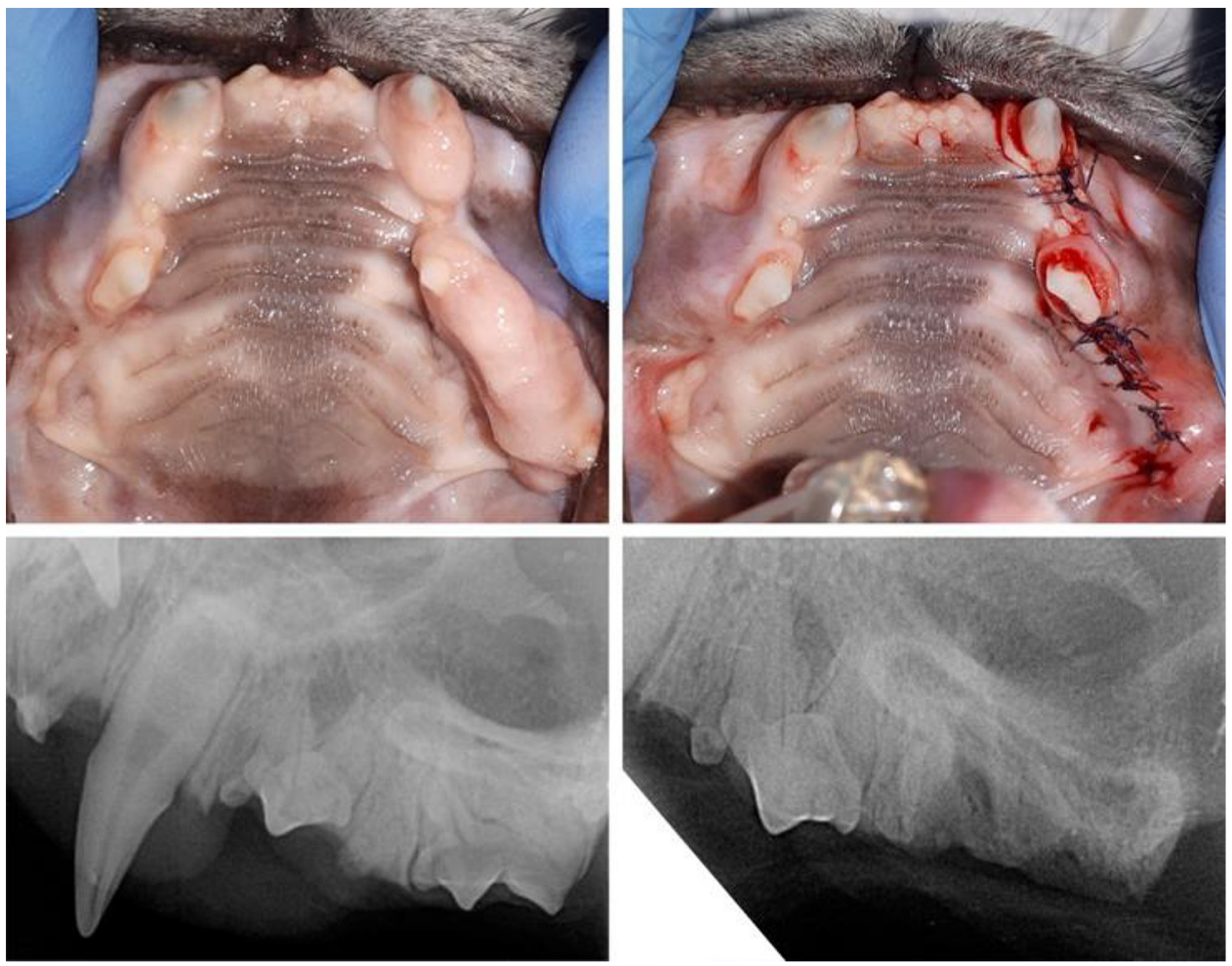

Fig. 7. Photographs and radiographs obtained pre and post second stage treatment (December 23, 2018) 